The Geneva Papers on Risk and Insurance, 14 (No. 53, October 1989), 296-307

\title{
The "Crisis" in Professional Liability Insurance
}

\author{
by Christopher J. Whelan* and Doreen McBarnet **
}

In many countries the relationship between professional liability insurance and the law is under stress. There is a widespread perception amongst professionals generally that the law is (and lawyers are) responsible for the "litigation explosion" - the huge increase in the number and size of claims against professionals, the huge rise in the level of insurance premiums and the alleged international contraction in the insurance market for indemnity cover. Neither the perception of a crisis nor the factors pointed to support it is universal. One of the intriguing observations by Goran Skogh in this volume is that in Scandinavia, at least, there is little perception of a professional indemnity crisis and liability insurance is relatively cheap. This is despite the fact that insurance is mandatory, deductibles are small and coverage often maximised to relatively small amounts.

Yet perception can outweigh experience. Increasingly if the crisis has not yet arrived in some countries in Europe, professionals nonetheless will look across the Atlantic and see the "future".

Certainly firms and professionals in virtually every profession and in most countries have experienced an increase in the size of claims. For the medical profession in the UK, the increase in the size of claims has outpaced the rate of inflation (Fenn and Whelan, 1989). No doubt this is the case for most other professions. But it is probably the accounting profession which has, more than any other, witnessed the greatest growth in the size of claims. It is in accountancy that even individual claims reach mega level. In the USA Arthur Anderson has been the subject of a $\$ 270$ million claim by the British government in respect of the collapse of the De Lorean car factory in Northern Ireland; and Peat Marwick a total $\$ 400$ million in ten claims in respect of the collapse of the Oklahoma-based Penn Square Bank. Over a five year period 1980-85, Arthur Anderson paid out a total of $\$ 137$ million; Peat Marwick $\$ 19.4$ million. In 1987, Grant Thornton paid $\$ 80$ million in settlement of a claim following the collapse of the Ohio-based Home State Savings Bank.

There has also been an increase in the number of claims. Thus, in the first year of the Institute of Chartered Accountants' (UK) Professional Indemnity Insurance Scheme (1971), only one firm in ten registered a claim. By 1983, one in five did so and it has been estimated that one in four did so in 1986.

* Lecturer in Law, University of Warwick School of Law.

** Senior Research Fellow, University of Oxford Centre for Socio-Legal Studies. 
Insurance premiums for professional indemnity cover have risen dramatically in recent years. The availability of insurance cover has also become difficult for some professionals. Small wonder perhaps that there is a widespread perception of a professional liability and indemnity insurance crisis and active professional responses to it.

\section{Professional responses}

\section{(i) Limitation of Liability}

The professional associations have, in the UK at least, not only blamed the law for an indemnity crisis but have been active in proposing changes in the law to deal with it. For example, the leaders of accountancy organisations have suggested that the liability of auditors be limited by statutory reform. Four options have been put forward for consideration : a ceiling on liability; a requirement for awards of damages to be apportioned according to each party's responsibility for the loss suffered (a proposal made also by the American Institute of Certified Public Accountants in 1986); a requirement of compulsory indemnity insurance; and allowing auditors to form companies, and thereby limit their liability. The medical profession has proposed that they receive Crown indemnity, thus insulating them from the rising cost of medical insurance.

Professions may wish and have proposed to limit their liability for negligence by contract with their clients. Posner has argued that "the most powerful economic objection" to the existing professional negligence system is the refusal of courts to enforce waivers of liability irrespective of the knowledge possessed by the client (Posner, 1977, pp. 157 159). Clearly, a legal system which imposes losses on professions which an informed client would be willing to bear himself in return for cheaper services is inefficient. Not only does such a rule impose excess insurance on some clients, thus lowering their welfare, but generates unnecessary legal costs - although in practice, as we shall see, the predominance of settlement out of court sets a de facto post hoc limitation on liability.

There may however still be good cost-saving reasons for ex ante contractual limitations, such as reduced bargaining and uncertainty costs. Exclusion of contractual limitations on liability is therefore not generally efficient and a superior approach would be to permit "reasonable" exclusions subject to the usual remedies governing contract. Such a proposal has been made by Epstein (1976) in the context of medical malpractice.

There may be other reasons supporting some type of limitation on damage awards, for example if the standard of care is too high or the awards made by the courts (or juries) are excessive. Both these grounds appear to have little foundation in the English context. Insurance reasons may also support some form of limited liability. It may be that some clients are in a better position to insure for larger losses than professionals. Thus, the limitation would reflect the need, in some cases at least, for risks to be shared between client and professional. This ground too appears dubious especially when liability insurance is widely available.

In response to these kinds of concern expressed not only by professional organisations - the UK Royal Commission on Legal Services recommended in 1979 that an inquiry should be set up without delay to review the issue of limited liability for claims of negligence - the UK government in 1987 set up a series of fact-finding inquiries into the professional liability problems of auditors, architects and surveyors. The studies will include the nature of the services provided and the duties and liabilities arising from it, the availability and cost of 
professional indemnity insurance, the application of the law of negligence and the way the law has changed, and the effects of these factors on the availability, cost and quality of professional services.

\section{(ii) Mutual insurance}

Meanwhile, professional organisations have made other suggestions for reform. These include the establisment of a Professions Insurance Bureau which would meet all claims in respect of uninsured or untraced professionals; a professional groups mutual insurance company, with very large catastrophic claims reinsured into the open market; immunity against legal action under the Financial Services Act (for a discussion of immunity in the context of legal services, see Veljanovski and Whelan, 1983); a cap on professional negligence liability by reference to how much insurance cover is actually available (in West Germany there is a limit on compensation for each audit); limits on the amount of damages that can be awarded in cases of professional negligence.

Some professions and individuals have already responded in a variety of ways. In the accounting profession, a mutual Accountants Professional Indemnity Company was recently formed offering professional indemnity cover up to $\$ 1$ million to firms with a fee income of up to $£ 3$ million and with up to 20 partners. At least 30 firms have signed up, with a further 30 likely to follow. The seven largest accountancy firms agreed in 1986 to set up a mutual self-insurance scheme to operate globally. The company would offer insurance at agreed commercial rates in order to fill gaps in the commercial market. Thus, different layers of cover would be obtained from separate insurance brokers.

So far as the professions are concerned then, there is a crisis in professional liability insurance, a crisis sufficiently serious to require major action. The blame for this crisis is repeatedly placed at the door of law and lawyers. Is this justifiable?

\section{The role of law}

Are changes in the legal standard of professional care responsible for the expansion in medical litigation? Are lawyers, the law and the courts merely "scapegoats"?

In the UK the standard of care which the law demands of a medical practitioner has remained remarkably constant over the last thirty years (Fenn and Whelan, 1989). Indeed, the courts have largely rejected attempts to widen the scope of liability by way, for example, of a wider definition of negligence, a duty to warn of risks or the introduction of the duty of informed consent. The standard test of medical negligence was set down in 1957 by the High Court in Bolam v Friern Hospital Management Committee ([1957] 2 All ER 118); a doctor is "not guilty of negligence if he acted in accordance with a practice accepted as proper by a responsible body of medical men skilled in that particular art". It is a conservative standard which leaves to the profession itself the task of determining whether the conduct in question conformed with the standard of care.

In the accountancy and other professions, by contrast, the scope of civil liability has expanded during this period. Accountants may be liable not only under the terms of contracts with their clients for failure to exercise reasonable care and skill. Contractual liability does not preclude tortious liability, which may extend beyond and may not be excluded by contractual terms (JEB Fasteners Ltd v Marks, Bloom \& Co [1983] 1 All ER 583). More 
importantly, liability, in appropriate circumstances, will extend beyond their clients to third parties. Accountants, for example, owe a duty of care to third parties whose reliance on accounts, audited or prepared by an accountant, for any reasonable purpose should be within the accountant's contemplation at the time of the audit or preparation. Since much of accountants' work in the corporate world, and indeed the work of other professionals, is for the benefit of "third parties" legally defined, and since third parties of all kinds will rely on much of the work performed - indeed this is the reason for audits by accountants - the scope for liability appears to be enormous. To what extent is this a reality?

In a recent UK case involving the accounting firm of Touche Ross, the issue arose, to whom does an auditor owe a duty of care? Does the duty extend to actual shareholders and investors in the company and to potential investors such as takeover bidders? In this case, a company named Caparo took over another, Fidelity, and subsequently sued Touche Ross for negligence in auditing Fidelity's accounts. There are three principles in law which apply to determine the extent of auditor's responsibilities: (i) was the likelihood of economic loss arising from a lack of care foreseeable; (ii) was the negligent misstatement (if that proved to be what it was) made in a situation in which there was a close and direct relationship, and in which the auditor should have known that Caparo was a member of a limited class who were likely to rely on the statement; (iii) was the imposition of liability for economic loss flowing from the misstatement fair, reasonable and just?

The first judge, Sir Neil Lawson, held that economic loss to investors in a company was foreseeable if the auditor's made a negligent misstatement in their report. However, he found that there was no close and direct relationship between the parties; Caparo was not a company which Touche Ross should have known were going to rely on their report; nor was it a member of a limited class of potential investors about whom Touche Ross should have known. On appeal, the Court of Appeal unanimously agreed with this conclusion. To quote the judge, it would not be "fair, reasonable or just to impose a common law duty on the auditors of a public company which would create a liability for an indefinite period to any member of the public who chose to rely on the auditor's report to invest in the company, or to lend money to the company, or to give credit to the company". The Court of Appeal also found that the relationship between the auditor and potential investors lacked sufficient proximity.

In other words, while the principles of law have unlocked the door for potential claimants, the courts have yet to open the door. Occasional judgements do widen the scope of liability. Thus, in the Caparo case itself, a majority of the Court of Appeal held, for the first time and disagreeing with the first judge, that auditors owe a duty of care to individual shareholders; the relationship is sufficiently proximate: "the touchstone of proximity... was the voluntary assumption of direct responsibility... in circumstances equivalent to contract". It is likely that accountants will again view this decision as opening up the way to liability that the judge described as "indeterminate, unlimited as to quantum, as to time and as to the identity of the beneficiaries". On the other hand, it is hard to defend an argument which attempts to equate the audit function with that of a contract. The auditor is exercising a "public" responsibility, to detect fraud and oversee the disclosure of financial information. Moreover, although the contractual relationship is between the auditor and the company, the contract is made on the company's behalf by the shareholders and the fee is paid out of company funds otherwise available for distribution to the shareholders. The menbers of the class of shareholders could also be precisely ascertained at any point in time. 
So far as formal law and court policy in the UK are concerned then the propensity of professionals to focus on the law as the potential "culprit" in the professional indemnity insurance crisis is misplaced. Indeed, in focussing on the role of law there is a danger that other factors may be ignored, or that complex causes may be oversimplified. Law may have a part to play in explaining problems with professional insurance, but as part of a more complex interaction of factors.

Peter Cane, in this volume, also addresses the issue of whether lawyers, the law and the courts are to blame for the crisis. He points to a range of other factors which affect premiums: claims-consciousness; the number of claims against the particular insured; the amount of investment income which the insurer can generate, the cost of reinsurance and the insurer's need to make a profit; the demand for professional indemnity insurance; the cost of legal services; the type and quality of service; the size of the insured's business; the limits of the indemnity selected. Cane argues that recent changes in liability rules could not have justified more than a very modest increase in insurance premiums; that other factors are more likely to have precipitated the large increases; and that structural features prevent liability rules having a direct or discernible effect on the cost of insurance.

Cane concedes that there may be a relationship between liability rules and premiums, but the assumption that it is a direct and simple relationship is rejected. Indeed, factors such as uncertainty in the law may be more important than change in the law itself in explaining increases. Cane concedes that the causes of the recent crisis require more work if they are to be explained. His analysis and that of others suggests, however, that uncertainty in the law and the context of professional indemnity insurance may be just as important a factor in any analysis as the law itself.

David Oughton, in his paper, addresses this question in a different way and asks whether it is the context of professional indemnity insurance which affects liability rules rather than vice versa. In particular, he asks whether the introduction of a requirement of compulsory third party insurance has a potential to trigger off an expansion in the tortious liability of a professional. In other words, do the courts take the presence of insurance into account? If this turned out to be the case, there would be a number of important implications. Such a development would lead to uncertainties amongst insurers as to where liability would stop. This uncertainty is likely to lead to a substantial increase in premiums, and to the introduction of other defensive tactics by insurers.

Clearly though, the relationship between the cost of professional indemnity insurance and the context of legal rules which regulate the liability of professionals is one which requires detailed and careful analysis in future research.

Recognising that law operates in a complex interaction with other factors, however, also indicates the need to explore contextual issues, wider than the law itself, in explaining the current problems in professional insurance. These include the insurance business, and the uncertainties involved in it, and the profession themselves.

\section{Insurance and uncertainty}

There are different kinds of uncertainty. Some of these - the legal standard, the impact of insurance on the standard, the number and size of potential claims and their range - have been identified already. These uncertainties are especially important in the calculation of professional negligence risks due to the "long tail": the lengthy period between the claim and its settlement. 
Underwriters find it difficult to finalise the results of any particular insurance year until all potential claims, which may take a decade or more to settle, have been disposed of. They also find it difficult to calculate the risks involved in professional insurance. As a result, premium levels may be calculated on an unsound basis, and claims payouts may in a given year exceed premium income. If the insurance companies are reluctant to accept professional cover or if investment income on the advance premiums is inadequate, professional indemnity insurance premiums are bound to rise sharply. This is precisely what happened post1982. With reinsurance companies facing heavy losses, they refused to handle indemnity insurance business; and investment income declined along with interest rates.

Faced with this new environment prime insurance companies had to raise premiums generally. They had to raise them faster in the context of professional indemnity insurance because of the "long tail" problem and the uncertainty about the number of claims for which they would be responsible and the amount such claims would cost. It is only in the latter part of the 1980s that the insurance companies have been able to determine the actual profit and loss for each year. To the extent that premiums rise and fall as a result of problems in the market for professional liability insurance, it is these problems which are responsible for the crisis.

\section{Role of professions}

Another crucial factor is the role of the professions themselves. Most professions have expanded the range of both the services they provide and the clients they serve. For this reason the context of professional work may be crucial to understanding the relationship between law and professional liability insurance. There are three important questions here: what work is done by the professional, how is the profession structured, and the question of moral hazard and professional control.

\section{(i) Work}

The expansion in the work performed by professionals and its relevance to professional liability insurance is illustrated by the accountancy profession in the UK. Large accountancy firms are no longer divided into separate departments providing simply audit, accounting, finance and taxation services. Firms now increasingly offer other services relating to corporate insolvency, pensions, investments, wills, insurance, acquisitions and mergers, corporate finance schemes and management consultancy. Moreover, the responsibilities and skills which have to be exercised by accountants have grown. Thus, the traditional role of accountants as auditors, that is, to "police" the disclosure of corporate financial information, has expanded enormously in recent years: all business providing financial services, regardless of size or status will be required to appoint auditors under the Financial Services Act 1986, and the auditors will have a new role to report to regulatory authorities if warranted by considerations of investor protection; under the Banking Act, some information uncovered during and audit must be reported to regulators; a similar provision, relating to concern about the financial viability of a client, has been placed upon auditors by City of London self-regulatory organisations. The practitioner's role as an adviser and overseer of the performance and viability of companies which are struggling to survive has been expanded following the Insolvency Acts 1985 and 1986. Legal rules are slowly but surely replacing the traditionally "subjective" approach taken by accountants, spurred on by the European Community harmonisation programme (see McBarnet and Whelan, 1989) and the professionals 
own statements of standard accounting practice. The profession itself in seeking new markets is offering a more complex "package" of services: "Audit Plus", for example, which combines auditing with business advice, is offered by Binder Hamlyn. Distinctions between different categories of work have become blurred. The "public" role of the accountant - verifying that the company's accounts give a true and fair view of its financial health and detecting and reporting fraud - has merged, on occasion, with its "private" role, which requires accountants to act in the interests of their clients. The potential conflicts of interest are recognised by the profession and by regulators; the European Community Eighth Directive is concerned with the independence of auditors.

However, the point is that, as the commercial and regulatory role of the accountancy profession has expanded - and the larger firms are in the process of "exporting" their version of accountancy to other countries - the problems of managing risk in the provision of services has grown alongside, or even ahead of it. A cursory glance at other professions would almost certainly reveal a similar picture. Whether through the development of new technology, the apparently inexorable growth in inter and intra-professional competition, changes in the structure and composition of professions or whatever, most professions are delivering services of a different kind and in a different manner than the "traditional" models of profession would suppose. This "context" may be of crucial importance in unravelling the relationship between law and insurance.

\section{(ii) Structure of professions}

In the same way that the range of services performed by a profession and the way those services are delivered can affect the relationship between law and indemnity insurance, so can the structure of the profession itself. It is becoming less accurate to think in the traditional terms of a homogeneous, united self-regulating profession. It is more accurate now to view professions as stratified and increasingly heterogeneous. One consequence of this fact, especially when viewed in conjunction with the enormous growth in the size of many professions, is an increase in intra-professional competition, specialisation and the fragmentation of diffuse interests. Dynamics within the profession have thus become an especially important factor in understanding the insurance requirements of, and problems posed by, groups within professions,.

This is illustrated in the paper in this volume by Bowles and Jones. They use a public choice analysis to explain the current structure of premiums for professional indemnity in the UK medical profession. This analysis reveals that the influence of a minority of relatively risky medical practitioners in the establishment of those premiums for which collective responsibility is shared can be great, and that the structure of premiums will reflect those who are prepared to incur the costs of political influence.

\section{(iii) Compulsory Insurance, moral hazard and professional control}

For some professionals, the "burden" of insurance has been made compulsory, either by the legislature or by the profession itself. Thus, in the UK, accountancy firms wishing to undertake investment business must, in order to obtain "professional body status" from the Securities and Investment Board, have compulsory professional indemnity insurance. Moreover, the Institute of Chartered Accountants has proposed to make compulsory professional indemnity insurance a condition of obtaining renewed practising certificates. Professional associations can have an influence on the level of cover required also. Prescribed 
cover for UK accountants is based on a multiple of three times gross fees or 30 times the largest single fee from one source, whichever is the higher. The result is that premium levels often exceed $3 \%$ of gross fees for a firm with a clean claims record.

In this volume, Faure and Van den Bergh address the question of whether liability insurance for professional services should be compulsory. Their analysis of the costs and benefits of such schemes, although focussing on Belgium, has implications for all countries for three reasons: they consider the rationales for compulsory liability insurance; they analyse the insurance practice from an efficiency viewpoint, focussing on the level of premiums, moral hazard and adverse selection problems: and they provide some analysis of distributive effects. The authors expressly attempt to generalise the conclusions for other legal systems.

One of their conclusions is that the most serious problems in the area of compulsory liability insurance for professionals in Belgium is an almost incurable moral hazard problem. This is due to a large extent to the rules of professional ethics which prevent monitoring by insurance companies. Another is that premiums exceed actuarily fair levels due to three factors: a lack of individualisation of premiums; certain rules of professional ethics, particularly the requirement for secrecy; and concentration on the insurance market.

Goran Skogh uses a transactions cost theory of insurance as an explanatory framework and analyses accountants, barristers and estate agents' insurance in Sweden, Denmark, Norway and Finland. Using this framework, Skogh argues that the rationale for insurance is that the purchase of a policy reduces the costs of contracting which, with the problem of free-riding by non-insured professionals, justifies professional associations requiring compulsory insurance and acting as agents for members in negotiations on price and coverage and in the claims settlement process (the courts and legislature have a limited role).

Skogh concludes that the Scandinavian system is efficient in that, on balance, it sets professional liability at a socially optimal level: professional associations and insurers are the most competent parties in society regarding the evaluation and pricing of professional liability: few cases are taken up by the courts. There are, however, two negative effects of compulsory, uniform and all-inclusive insurance. If moral hazard is to be compensated for, the social control exercised by the professional associations must be considerable. The other negative effect is the monopolistic power of the associations to control the price.

David Oughton also reviews the advantages and disadvantages of compulsory third party liability, but he does so in the context of insurance practices which might follow an expansion of tortious liability. He agrees with Faure and Van den Bergh that to make third party insurance compulsory might not be of any benefit since there would be no effective means of controlling the problem of moral hazard. He reviews recent developments in English law which have expanded the scope of losses compensatable through the tort system, and also the potential for disclaimers of liability. He concludes that a move away from third party insurance might be a possibility; that property interests might be better protected by first party loss insurance or an action for damages for breach of contract; and that personal injury losses might be better dealt with by means of a compensation fund financed out of taxes and levies upon professional persons.

The professions' kneejerk tendency to blame the law for problems in liability insurance should therefore be tempered by a closer look at the ways in which their own activities have contributed to any crisis and indeed continue to frustrate proposals for dealing with it. 
Indeed, ironically, in many ways the law, or at least the legal process, mitigates liability costs. The legal process in reality involves barriers to recovery, which make it extremely difficult for victims to effectively enforce liability claims.

\section{Barriers to recovery}

In most legal systems, individual claimants face a series of hurdles which have to be overcome if they are to bring a claim against a professional. There is evidence in the UK suggesting that clients of professional services are the consumers least likely to complain or to seek third party advice (OFT, 1986). If barriers are removed, more claims may be brought with obvious effects on insurance. Barriers which will be considered here are the law, information, costs and the availability of legal services.

One example of how the law might act as a barrier to claims is in medical cases, where the victim not only has to prove that the practitioner was negligent but also that the cause of his injuries was that negligence and not something else. Medical treatment entails inherent risk, both of faillure and of complications, some of which may be statistically predictable. There may be several possible factors, of which negligence is only one, which may have caused the injuries or disabilities.

Victims of professional negligence face other barriers to bringing a claim, the most important of which is informational asymmetry. Many victims do not know that the injury, disability or loss is the result of negligence. In medical cases, patients may shrug off ill effects as the inevitable side-effects of treatment. In other cases of professional services, consumers will not be aware of what services they need nor whether they have in fact been supplied (Veljanovski and Whelan, 1983).

Informational asymmetry is an inherent part of many professional-client relationships. The law and the legal system could be used to redress the balance. The law could impose a "duty of candour" on doctors, obliging them to explain to patients what went wrong and to disclose information. The legal system could ensure that legal advice, assistance and representation is available for the clients of professional services. In practice, however, potential claimants in certain fields such as medical malpractice require not only lawyers to represent them, they need lawyers experienced in medical litigation. In the UK, the unsophisticated lawyer is immediately identified by the health authority or the insurance company and exploited. Lack of information makes even more difficult the task of proving that it was the negligence which caused the injuries.

In practice, very few claims against professions result in trials in court. Most claimants, however meritorious their claims, settle out of court because settlement is usually much cheaper than litigation. Fenn and Vlachonikolis propose a formal model of the process and present an empirical specification. Although the analysis reported is provisional and based on a fairly small sample, the findings suggest promising lines of enquiry. In particular, the authors conclude that the settlement process should perhaps be viewed as a way of exchanging information about changes in reservation prices - through a process of offer and rejection of offer - while minimising the costs of strategic behaviour.

So far as barriers to recovery are concerned, quite simply the costs involved in legal systems which require a claimant to prove fault are great. Thus, fee arrangements between the lawyer and his client, the availability of legal aid, alternative methods of delivering legal 
services are all relevant to the issue of professional indemnity insurance. This is manifest by the reactions of the professions to proposals for changes in the way legal services are provided to potential victims of professional negligence. The British Medical Association recently protested to the Law Society, the major legal professional association, about advertisements by lawyers which encourage people to come forward if they believe they may have a claim for medical negligence or other personal injury.

The legal process and access to it limit the number of claimants and legal policy positively encourages claimants to settle out of court. The legal process, far from causing a litigation explosion, actually helps suppress litigation and liability costs at the expense of the injured party.

\section{No-fault compensation fund: a way forward?}

In the context of both barriers for victims and insurance problems for professionals, there are attractions in the idea of a no-fault compensation fund. This is one of the most widely-considered proposals in the field of professional negligence, particularly in the context of the medical profession. For the victim, it removes the difficulties of proving fault and of showing that the injuries were caused by negligence. For the professional, it may reduce the insurance premium by avoiding the enormous administrative costs incurred in litigation.

The incentives for the production of medical accidents and the compensation of victims can be influenced by a variety of instruments. With this and so many proposals being considered in response to the perceived crisis, there needs to be a framework for evaluating the present negligence regime relative to possible alternatives. This is a task which has been addressed in a preliminary way in the context both of legal services and medical practice. (See Veljanovski and Whelan, 1983; Whelan, 1988.) However, in this volume, several authors consider more substantially what framework is appropriate. Patricia Danzon, in the context of iatrogenic injuries, uses welfare loss as the criterion for evaluating four alternative liability rules: an imperfect negligence system; first party insurance; strict liability financed through private liability insurance purchased by physicians; and a no-fault compensation fund financed by general revenues. Both allocative and distributive effects are considered. She also applies the existing literature on law and economics to the context of medical care.

Danzon's analysis suggests that the optimal liability regime may be different for different types of injury. She recognises that several of the key parameters required for the overall evaluation of alternative liability rules are in principle unobservable. This raises important questions regarding the role of research in this area, the assumptions which have to be relied upon, whether model-building may be more appropriate in certain circumstances and the extent of the need for contextual and empirical data.

Gravelle adds to Danzon's discussions of various instruments which influence care and compensation through his examination of the potential of no-fault compensation funds. His preliminary analysis suggests that this particular liability regime has some attractive features - victims are more likely to receive compensation; administrative costs are low. The implications of a no-fault scheme are also considered by Bowles and Jones in the context of their public choice approach to medical indemnity in the UK. Their concern is that such a scheme would insulate doctors further from the effects of professional negligence. Gravelle also 
recognises the reduced incentives on doctors to take care as the major disadvantage of nofault compensation funds. However, he believes that this can be dealt with by allowing the compensation fund to recoup payment from particular doctors. If insurance companies design premiums appropriately, moreover, an incentive to take some care could be retained. At the least, Gravelle notes, a compensation fund with subrogation rights would repay more detailed analysis.

\section{Role of research}

The intrinsic complexity of medical practice illustrates the difficulties of research. The difficulties of building positive models of decision-making, informational asymmetry and information costs, and the lack of systematic empirical data all combine to hamper the task of researchers in this area. For Hugh Gravelle the evaluation of alternative policies poses fundamental problems. In the first place, the evaluation of policies requires (a) a clear statement of the objectives; (b) positive models of the behaviour of decision-makers and their responses to policy; and (c) detailed empirical information. None of these requirements is likely to be easily satisfied in the case of medical accidents. Secondly, ex post criteria in assessing policies suffer from a number of serious drawbacks, concerning the concept of ex post compensation and the ability to rank alternative policies. Thirdly, although ex ante criteria are therefore essential, they too create difficulties arising from the assessment of probabilities. Fourthly, predicting the effects of alternative policies requires models of doctors, patients, insurers, the courts and regulatory authorities; such models are difficult to construct and the objectives of each group difficult to describe. Moreover, the pervasiveness of information asymmetry between the different decision-makers must be recognised in formulating policies.

Medical malpractice is also the focus of the paper in this volume by Coyte, Dewees and Trebilcock, members of the Health Provider Liability Task Force in Canada. They seek in a long-term research project to describe the medical malpractice trend in Canada and its determinants. The authors review Canada's health care and tort system and present a general theoretical framework that they plan to employ to describe both the malpractice process as well as the pattern of medical practice in Canada. The array of hypotheses for the trends in malpractice litigation which the research team plan to test and the data which will be required in order to test them are also, tentatively, presented. Theirs is thus a wideranging paper, and one which addresses the question of which kind of research can and should be done in this case. Research which reveals convincingly the possible determinants of both the trends in malpractice claims and settlements and their impact on the practice of medicine would be of major international importance. The agenda presented via a relatively simple model is nevertheless quite ambitious. An extensive data set (the claims files held by the Canadian Medical Protective Association which covers 85 per cent of all physicians, and information on the practice of medicine from the ten provincial health insurance plans over the period (1971-87) will be used as the basis of empirical work on the determinants of the frequency of malpractice claims, the size of settlements and the response by physicians to the perceived malpractice crisis. The empirical study will attempt to answer a wide range of questions: what factors determine the probability of successful litigation and the subsequent award of damages; what is the aggregate claims probability; how do factors (including malpractice litigation) interact with each other to influence the practice of medicine and the level of medical care? 
While we must await the results of this ambitious large-scale study, Lois Quam in her paper questions whether the framework proposed in the Canadian study sufficiently reflects the intrinsic complexity of medical practice. She conludes that econometric equations cannot replace careful model-building; the former may be attractive for their simplicity but the latter accepts the world as complex. Policy-makers have to live in the "real world".

\section{Conclusion}

In analysing the "crisis" in professional liability insurance simple models must likewise be overruled. A complex interaction of legal, insurance and professional factors is involved, all requiring much more empirical and comparative research. The professions' tendency to treat the problem as a legal disease may be another case of mistaken diagnosis.

\section{REFERENCES}

EPSTEIN, R. 1976 "Medical malpractice: the case for contract", American Bar Foundation Research Journal 87

FENN, P. and WHELAN, C.J. 1989 "Medical Litigation: Trends, Causes, Consequences", in R. Dingwall (ed.), Socio-Legal Aspects of Medical Practice (Royal College of Physicians, London) 1989.

GWILLIAM, David 1988 "Does Care Extend Beyond the Contract?", Accountancy, May, p. 17.

HARRIS, D. R. et al 1984 Compensation and Support for Illness and Injury (Clarendon Press, Oxford).

McBARNET, D. and WHELAN, C. J. 1989 "Regulating Accountancy: The Limits of the Law", in T. Hopwood (ed.) Accountancy and Law.

Office of Fair Trading 1986 Consumer Dissatisfaction (HMSO, London).

POSNER, R. 1977 Economic Analysis of Law (Little Brown).

VELJANOVSKI, C. G. and WHELAN, C. J. 1983 "Professional Negligence and the Quality of Legal Services - An Economic Perspective", 46 Modern Law Review 700

WHELAN, C.J. 1988 Litigation and Complaints Procedures: Objectives, Effectiveness and Alternatives, 14 Journal of Medical Ethics 70 